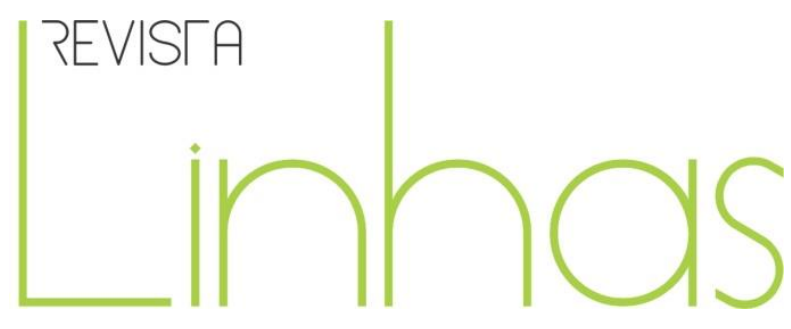

\title{
O Núcleo de Estudos Afro-brasileiros da Universidade Federal do Paraná (NEAB-UFPR) como espaço de formação continuada: as produções monográficas sobre educação infantil
}

\begin{abstract}
Resumo
Este artigo apresenta uma análise dos trabalhos monográficos realizados pelos concluintes dos cursos de especialização em Educação das Relações Étnico-Raciais, ofertados entre 2011 e 2014 pelo Núcleo de Estudos Afro-Brasileiros da Universidade Federal do Paraná (NEAB-UFPR), cujos temas de pesquisa foram relacionados com a Educação Infantil. Foram selecionados oito trabalhos, que abordaram literatura infantil, implementação do Art. 26 da Lei $n^{\circ}$ 9.394/96 em municípios paranaenses, história e cultura afro-brasileira e religião de matriz africana. As pesquisas evidenciaram dados positivos quanto ao trabalho da Educação das Relações ÉtnicoRaciais (ERER) na Educação Infantil. Outro aspecto apontado pelas pesquisas foi a necessidade de mais discussão sobre a temática da ERER na formação das professoras de Educação Infantil, bem como nas políticas educacionais municipais.
\end{abstract}

Palavras-chave: Educação de Crianças. Universidade Federal do Paraná - Núcleo de Estudos Afro-brasileiros. Relações Raciais. Professores-Formação.

\author{
Gioconda Ghiggi \\ Instituto Federal do Paraná - \\ IFPR - Curitiba/PR - Brasil \\ gighiggi@yahoo.com.br
}

\section{Para citar este artigo:}

GHIGGI, Gioconda. O Núcleo de Estudos Afro-brasileiros da Universidade Federal do Paraná (NEAB-UFPR) como espaço de formação continuada: as produções monográficas sobre educação infantil. Revista Linhas. Florianópolis, v. 19, n. 40, p. 294-306, maio/ago. 2018. 


\title{
Afro-brazilian studies nucleus in the Federal University of Paraná (NEAB-UFPR) as a space for continued training: the monographic productions in child education
}

\begin{abstract}
This article presents an analysis of the monographic production done by the students attending the EthnicRacial Relations Education postgraduate course, offered between 2011 and 2014 by Afro-Brazilian Study Center of the Federal University of Paraná (NEABUFPR), whose research themes were related to Early Childhood Education. Eight papers were selected, being about children's literature, implementation of the article 26 presented in Law 9394/96 in the municipalities of Paraná Afro-Brazilian history and culture and the origin of African religion. The research evidenced positive data regarding to the production of Ethnic-Racial Relations Education (ERER) in Early Childhood Education. Another aspect pointed out by the researches was the need for more discussion about ERER in the Early Childhood Education teachers training, as well as in the municipal educational policies.
\end{abstract}

Keywords: Children's Education. Federal University of Paraná - Afro-Brazilian Studies Nucleus. Racial Relations. Teachers -Training. 


\section{Introdução}

Os Núcleos de Estudos Afro-Brasileiros (NEABs) são importantes promotores de formação sobre a Educação das Relações Étnico-Raciais, como podemos observar no Plano Nacional de Implementação das Diretrizes Curriculares Nacionais para a Educação das Relações Étnico-Raciais de 2013. No item 6.1, do referido Plano, entre os objetivos previstos para os NEABs temos:

a) Colaborar com a formação inicial e continuada de professores(as) e graduandos em Educação das Relações Étnico-Raciais e Ensino de História e Cultura Afro-Brasileira e Africana, de acordo com o disposto na Resolução CNE/CP n01/2004, no Parecer CNE/CP n 03/2004 e nas Leis $n^{\circ}$ 10.639/03 e nं 11.645/08;

b) Elaborar material didático específico para uso em sala de aula, sobre Educação das Relações Étnico-Raciais e História e Cultura Afro-Brasileira e Africana, que atenda ao disposto na Resolução CNE/CP n 01/2004 e no Parecer $\mathrm{CNE} / \mathrm{CP}^{\circ}$ 03/2004;

c) Mobilizar recursos para a implementação da temática, de modo a atender às necessidades de formação continuada de professores(as) e de produção de material didático das Secretarias Municipais e Estaduais de Educação e/ou de pesquisas relacionadas ao desenvolvimento de tecnologias de educação que atendam à temática;

d) Divulgar e disponibilizar estudos, pesquisas, materiais didáticos e atividades de formação continuada aos órgãos de comunicação dos sistemas de educação. (BRASIL, 2013, p. 44)

Seja na formação inicial ou na continuada, os NEABs são fundamentais na articulação e implementação de discussões sobre a Educação das Relações Étnico-Raciais (ERER), nos espaços acadêmicos, movimentos sociais e comunidade. Com relação à formação continuada, pesquisas apontam esta como essencial para ressignificar as práticas dos professores, colaborar para um novo olhar frente às questões raciais do cotidiano, colocando a escola como um espaço de respeito, diversidade e ruptura com práticas reprodutoras de discriminação e racismo (FREITAS, 2010; FELIPE, TERUYA, 2010; FELIX, 2010; CANDAU, 2011; PALÚ, 2011; MARTINS, 2012; PAULA, 2013; LUIZ, 2013; FELIPE, TERUYA, 2013; SILVA, 2014; BUZATTO, 2015, FRIEDRICH, 2015; MACHADO, 2015).

O Núcleo de Estudos Afro-Brasileiros da Universidade Federal do Paraná (NEABUFPR) é um importante promotor de cursos de formação destinados aos professores da Rede Pública de Curitiba e de outros municípios do Paraná. Entre os cursos realizados, 
destacamos as especializações lato sensu realizadas entre 2011 e 2015, que resultaram em 100 monografias. Ao consultar estes trabalhos de conclusão, nos perguntamos: a Educação Infantil esteve presente como objeto de investigação dos participantes destas especializações?

Ao realizarmos a análise dos textos, localizamos oito produções relacionadas com a Educação Infantil, que apresentaremos neste artigo. Antes de procedermos à análise dos trabalhos selecionados, apresentamos uma reflexão sobre o NEAB-UFPR e sua dimensão formativa.

\section{Dimensão formativa do NEAB-UFPR}

O NEAB-UFPR foi constituído em 2004 com o objetivo de ser um "centro de referência que articule e promova atividades de ensino, pesquisa e extensão relacionadas ao campo de estudos afro-brasileiros", conforme consta na página institucional da UFPR ${ }^{1}$.

A origem do NEAB-UFPR está relacionada com os debates em torno das políticas de cotas, ocorridas entre 2001 e 2004, promovidos com a comunidade acadêmica pela UFPR e iniciativas de grupos de estudantes e professores. Cabe destacar que a temática racial na universidade esteve presente em ações anteriores, iniciadas nos anos de 1990, com estudantes do movimento negro, professores e servidores (AMORIM, 2016).

O NEAB-UFPR, desde 2004, realiza uma série de ações: apoio acadêmico, seminários, palestras, pesquisas, cursos e minicursos, conferências, produção de materiais, debates, encontros, entre outros. Ao analisar as diversas atividades, Ghiggi (2017) sistematizou as atuações em quatro dimensões:

- Institucional: proposição e execução de políticas institucionais que busquem ampliar o debate sobre a temática racial, acompanhar os processos seletivos de estudantes e orientar acadêmicos.

- Ensino, Pesquisa e Extensão: promoção do debate sobre a ERER nas políticas institucionais relacionadas com os três pilares da universidade, buscando combater o preconceito e o racismo presentes no interior da academia.

\footnotetext{
${ }^{1}$ Disponível em: <http://www.ufpr.br/portalufpr/pesquisa-e-inovacao/nucleos/>.
} 
- Movimento Negro: promoção de discussões quanto às relações raciais, situações de discriminação e preconceito dentro e fora da universidade.

- Formativa: realização de cursos e eventos direcionados aos diversos públicos, principalmente aos professores da rede pública.

Com relação à dimensão formativa, entre 2004 e 2015, o NEAB-UFPR promoveu cursos de extensão (120 e 178 horas), aperfeiçoamento (180 horas) e especialização (360 horas) sobre a ERER, e contou com a participação de aproximadamente 1.500 professores $^{2}$ (GHIGGI, 2017). Entre as ofertas formativas, e considerando a característica de pesquisa que permeia a formação lato sensu, foram analisadas as monografias referente à Educação Infantil produzidas nos três Cursos de Especialização em Educação das Relações Étnico-Raciais.

\section{A educação infantil nas produções monográficas da formação lato sensu}

O NEAB-UFPR ofertou, entre 2011 e 2015, três cursos de Especialização lato sensu, sendo que os dois primeiros foram organizados na modalidade presencial e o terceiro, ofertado na modalidade a distância. Os cursos foram viabilizados por meio de financiamento do Programa de Ações Afirmativas para a População Negra nas Instituições Federais e Estaduais de Educação Superior (UNIAFRO).

O primeiro curso de Especialização em Educação das Relações Étnico-Raciais, modalidade presencial, foi realizado entre 2011 e 2012. O curso iniciou com 42 cursistas e finalizou com 18 especialistas. A segunda turma, também ofertada na modalidade presencial, foi realizada entre 2013 e 2014; iniciou com 46 discentes e, destes, 17 finalizaram o curso com a entrega da monografia. O terceiro curso de especialização ocorreu entre 2013 e 2015, com a oferta de 200 vagas distribuídas entre os municípios de Almirante Tamandaré (35 vagas), Araucária (35 vagas), Campo Largo (35 vagas), Curitiba (60 vagas) e Pinhais (35 vagas). Nesta última oferta, 65 professores finalizaram o curso com a entrega de monografias. Entre os objetivos dos cursos, podemos destacar:

\footnotetext{
${ }^{2}$ Este número representa os participantes dos cursos de extensão (120 a 178 horas), aperfeiçoamento (180 horas) e cursos de especialização ( 360 horas) promovidos pelo NEAB-UFPR. Os dados foram sistematizados com base nos relatórios dos projetos.
} 
implementar o Programa de Formação em Educação das Relações Étnico-Raciais e dar continuidade ao processo de formação de docentes das redes públicas com foco nas seguintes normativas: Artigo 26-A da LDB nº 9.394/1996, no Parecer CNE/CP nº 04/2004 e no Plano Nacional de Implementação das DCNERER (2013).

Considerando os dados apresentados, o número de concluintes com apresentação de monografias, tem-se o total de 100 trabalhos. Tivemos acesso a 89, dos quais oito versavam sobre a Educação Infantil.

A respeito do quantitativo de trabalhos (8), avaliamos como positivo dentro do quadro tão diverso e rico das produções realizadas pelos professores participantes (formação de professores, literatura, livros didáticos, mídia, mulheres negras, religião, racismo nas escolas, adoção, etc.).

Analisando especificamente as produções relacionadas com a Educação Infantil, observamos que os assuntos abordados foram: as práticas pedagógicas, levantamento de dados sobre ações afirmativas na produção acadêmica, a literatura infantil e personagens negros e a implementação da ERER na Educação Infantil nos municípios paranaenses.

A abordagem qualitativa foi predominante enquanto percurso metodológico. Os métodos mais utilizados foram: a pesquisa bibliográfica, a análise documental, observação e questionários. Os questionários possibilitaram ouvir os sujeitos, em sua maioria professoras, acerca de suas práticas e percepções quanto à ERER na Educação Infantil. Apresentamos, então, os principais resultados de cada trabalho envolvendo a Educação Infantil.

Iniciamos com o trabalho intitulado As micro-ações afirmativas nas pesquisas sobre Educação Infantil, de Fabricio (2015). O trabalho analisou como o brincar e a formação dos docentes, na perspectiva da ERER, estão presentes nas publicações nos Grupos de Trabalhos (GTs) 7 e 21 da Associação Nacional de Pós-Graduação e Pesquisa em Educação (ANPEd) e no repositório Scientific Eletronic Library Online (SCIELO). Para seu trabalho, a autora utilizou o conceito de micro-ações afirmativas de Jesus (2009), ou seja, "práticas pedagógicas de caráter anti-racista, comprometidas com a transformação do quadro de desigualdade étnico-racial que se evidencia na sociedade brasileira e, por consequência, nos cotidianos escolares" (JESUS, 2009, p. 01). Verificou-se, na análise realizada por 
Fabricio (2015), a pouca presença de micro-ações afirmativas nas pesquisas publicadas no Scielo, assim como nos GTs 7 e 21 da ANPEd. Fabricio (2015) aponta que

[...] já existem micro-ações afirmativas na Educação Infantil, através de práticas pedagógicas do brincar e de cursos de formação abordando a temática racial, contribuindo, ainda que timidamente, para uma educação para as relações étnico-raciais da criança pequena. Todavia, muito ainda há para se fazer, pois práticas racistas convivem, infelizmente, com micro-ações afirmativas, fazendo com que pesquisas e intervenções nos espaços da educação infantil sejam uma necessidade inadiável para o momento atual da educação da criança pequena no Brasil.(FABRICIO, 2015, p. 45)

Conforme afirma a autora, são necessárias mais intervenções com práticas pedagógicas afirmativas na Educação Infantil. Avaliamos que um dos caminhos, para efetivar a ERER na Educação Infantil, é ampliar o contato dos professores com os materiais oriundos de pesquisas e relatos de experiências, bem como ampliar o conhecimento sobre a legislação.

Sobre documentos e pesquisas, Ferreira (2015) analisou a temática da africanidade em 13 documentos (três artigos, quatro teses/dissertações e seis publicações) destinados à Educação Infantil. No trabalho intitulado Africanidades na Educação Infantil: perspectiva para o trabalho educativo com a criança pequena, a autora apontou que, além de questões práticas, os documentos apresentam "a história e a trajetória social das lutas por mudanças na educação brasileira, advindas de diversos setores sociais" (FERREIRA, 2015, p. 43). Com base nas reflexões de Ferreira (2015), os documentos apresentados são um importante subsídio teórico no campo das pesquisas sobre a ERER, os quais podemos utilizar nas formações continuadas dos docentes.

Sobre o tema da formação, o trabalho de Nascimento (2015), Coordenação pedagógica e práticas de (re)educação das Relações Étnico-raciais no município de Pinhais$P R$, buscou identificar se as ações formativas, desenvolvidas pela Comissão Permanente da Diversidade do município de Pinhais, contribuíram positivamente nas formações promovidas pelas coordenações pedagógicas dos Centros Municipais de Educação Infantil (CMEIs). A pesquisadora concluiu que, nos CMEls estudados, os dados analisados apontaram para referências de boas práticas envolvendo coordenação pedagógica e 
professores, mesmo apresentando algumas dificuldades, como a dinâmica de comunicação entre a Comissão e sujeitos que poderiam participar dos cursos promovidos.

Ainda sobre o Munícipio de Pinhais, Oliveira (2015) realizou uma pesquisa com o objetivo de "analisar quantitativamente como se efetiva a prática docente no que se refere à diversidade religiosa e sua relação com o estado laico no âmbito da educação infantil em CMEIs" (OLIVEIRA, 2015, p. 27). A coleta de dados foi realizada por questionários: no total, a autora analisou 24 formulários. O perfil dos profissionais que responderam ao questionário era: duas diretoras, três pedagogas e 19 educadoras. Entre os resultados apresentados, $46 \%$ responderam que costumam realizar orações com as crianças e $79 \%$ afirmaram que o planejamento tem como base o calendário cristão. A autora deixa claro que o objetivo de sua pesquisa não é discutir o Ensino Religioso na Educação Infantil, mas verificar se eram atendidos os pressupostos presentes nas Diretrizes Curriculares Nacionais para a Educação das Relações Étnico-Raciais, considerando as religiões de matriz africana como parte da cultura afro-brasileira, portanto, trabalhadas na Educação Infantil. Oliveira (2015) aponta que privilegiar apenas alguns "segmentos religiosos predominantes na nossa sociedade pode incorrer em uma prática discriminatória que reforça uma imagem negativa dos negros em nossa sociedade" (OLIVEIRA, 2015, p 34); assim, torna-se necessário o aumento de momentos formativos com o tema das religiões de matriz africana.

No trabalho de Rosa (2015), intitulado História e cultura afro-brasileira na Educação Infantil: a efetividade da Lei $n^{\circ}$ 10.639/03 no município de São José do Pinhais, o pesquisador aponta para um desconhecimento do previsto no Art. 26-A. Rosa (2015) apresenta como grande desafio o cumprimento das leis sobre a ERER na realização das práticas pedagógicas realizadas no cotidiano da Educação Infantil. A formação continuada também é evidenciada pelo autor, que coloca a troca de experiência como uma metodologia importante, facilitando assim as ações afirmativas sobre a temática das relações étnico-raciais (ROSA, 2015).

Keik (2015) apresenta uma reflexão sobre o trabalho que ela desenvolveu como docente de crianças pré-escolares, em um Centro Municipal de Educação Infantil no município de Almirante Tamandaré. Com o trabalho intitulado História e cultura africana e 
afro-brasileira na Educação Infantil, a autora coloca a importância de se apresentar uma imagem positiva dos referenciais africanos, de sua riqueza cultural, entre outros. Keik (2015) conclui que "a ação do educador compromissado em levar a cultura e a história da África e do afro-brasileiro ao cotidiano escolar é fundamental no rompimento com práticas não expressivas, bem como para o avanço qualitativo das relações raciais no âmbito educacional" (KEIK, 2015, p. 31). A autora coloca ainda o que o "o ensino da História e cultura Africana, nos faz reconhecer o que somos" (KEIK, 2015, p. 31).

Os trabalhos de lansen (2015) e Martins (2015) abordam a relevância da prática pedagógica com o uso da literatura infantil para as crianças. As pesquisas apontaram a importância dos personagens negros, como forma de valorizar a identidade das crianças negras e, nas crianças brancas, valores, respeito ao outro e reconhecimento das diversidades culturais. Iansen (2015) discorre sobre a opção pedagógica da literatura africana, na qual o professor "pode desenvolver o seu trabalho, voltado para o conhecimento da cultura afro-brasileira, pois através do lúdico a criança pode vir a internalizar novos conhecimentos" (IANSEN, 2015, p. 28).

Um ponto central de todos os trabalhos foi o professor, que esteve direta ou indiretamente envolvido: na análise de práticas pedagógicas e no conhecimento sobre a legislação pertinente da ERER. As políticas educacionais municipais, para implementar e/ou ampliar a ERER na Educação Infantil, precisam considerar este lugar fundamental dos docentes.

\section{Considerações finais}

Os documentos sobre a Educação das Relações Étnico-raciais (Parecer CNE/CP n $^{\circ}$ 03/2004 e o Plano de Implementação das Diretrizes Curriculares Nacionais para a Educação das Relações Étnico-Raciais), colocam os NEABs como importantes articuladores da formação dos professores. O NEAB-UFPR, cumprindo o previsto nas normativas, promoveu (e ainda promove) diversas ações formativas. Entre os cursos ofertados, foram analisadas as produções monográficas dos cursos de especialização oferecidos entre 2011 e 2015, que apresentam como objeto temáticas que envolveram a Educação Infantil. No total, foram localizados oito trabalhos, que após serem analisados, 
evidenciaram a necessidade de mais discussão sobre a temática ERER na Educação Infantil, principalmente na formação docente, além de um projeto educacional que inclua as normativas vigentes.

As pesquisas envolvendo a Educação Infantil no NEAB-UFPR estão presentes desde 2012, como observamos em Dias e Dalto (2016), As relações raciais na Educação Infantil: o que dizem as produções de conhecimento do NEAB-UFPR?, através de pesquisas e orientações de membros do Núcleo.

Finalizamos com os apontamentos das pesquisas de Vasconcellos (2004), Silva e Branco (2011) e Bento (2012) que afirmam que na Educação Infantil encontramos muitas situações de discriminação, em contradição com a crença da inocência e de um ambiente livre de preconceito. Pesquisas envolvendo uma instituição, um município e experiências diferenciadas são importantes para acompanharmos como o Art. 26-A da Lei $n^{\circ}$ 9.394/1996 vem sendo incorporado no cotidiano da Educação Infantil.

\section{Referências}

AMORIM, Silvia Maria. A permanência de estudantes negros (as) na Universidade Federal do Paraná: aspectos material e simbólico. 2016. Dissertação (Mestrado em Educação) Universidade Federal do Paraná, Curitiba. 2016

BENTO, Maria Aparecida Silva (Org.). Educação infantil, igualdade racial e diversidade: aspectos políticos, jurídicos, conceituais. São Paulo: Centros de Estudos das Relações de Trabalho e Desigualdades - CEERT, 2012.

BRASIL. Lei $n^{\circ}$ 9.394, de 20 de dezembro 1996. Estabelece as diretrizes e bases da educação nacional. Diário Oficial [da] República Federativa do Brasil. Brasília, DF, 20 dez. 1996.

BRASIL. Parecer CNE/CP nº 03, de 10 de março de 2004. Diretrizes curriculares nacionais para a educação das relações étnico-raciais e para o ensino de história e cultura afrobrasileira e africana. Brasília, 2004. 
BRASIL. Plano nacional de implementação das diretrizes curriculares nacionais para educação das relações étnico-raciais e para o ensino de história e cultura afro-brasileira e africana. Brasília: SECAD/SEPPIR, 2013.

BUZATTO, Odete do Rocio. Análise da formação docente para diversidade cultural na escola básica: as novas dimensões do trabalho pedagógico, 2015. Dissertação (Mestrado Profissional em Educação) - Universidade Federal do Paraná. Curitiba. 2015.

CANDAU, Vera Maria Ferrão. Diferenças culturais, cotidiano escolar e práticas pedagógicas. Revista Currículo sem Fronteiras, Rio de Janeiro, v. 11, n. 2, p. 240-255, jul./dez. 2011. Disponível em:<http://www.curriculosemfronteiras.org/vol11isszarticles/candau.pdf >. Acesso em: 03 dez 2017.

DIAS, Lucimar Rosa; DALTO, Helena Alves. As relações raciais na educação infantil: o que dizem as produções de conhecimento do Neab-UFPR. In: Copene Sul, Curitiba 2016.

Anais..., Curitiba, 2016.

FABRICIO, Barbara Louyse Zoelner. Micro-ações Afirmativas nas pesquisas sobre

Educação Infantil. 2015. Trabalho de Conclusão de Curso (Especialização em Educação da Relações Étnico-Raciais) - Núcleo de Estudos Afro-brasileiros, Universidade Federal do Paraná, Curitiba, 2015.

FELIPE, Delton Aparecido. TEARUYA, Teresa Kazuko. O outro na sala de aula: o cinema no ensino da história e cultura afro-brasileira na educação escolar. Revista Contrapontos Eletrônica, Itajaí, v. 10, n. 1, p. 82-89, jan./abr. 2010.

FELIPE, Delton Aparecido; TERUYA, Teresa Kazuko. Filmes e negritude em sala de aula: essa relação é possível? Revista ETD - Educação Temática digital, Campinas, v. 15, n. 1, p. 145-160, jan./abr. 2013. Disponível

em:<http://ojs.fe.unicamp.br/ged/etd/article/view/2907/3839>. Acesso em: 10 Dez. 2017.

FELIX, Sayara de Brito. Cabelo bom. Cabelo ruim: a construção da identidade afrodescendente na sala de aula. Revista África e Africanidades, Rio de Janeiro, Ano 3, n. 11, nov. 2010. Disponível em:

<http://www.africaeafricanidades.com.br/documentos/01112010_25.pdf>. Acesso em: 03 Nov. 2017.

FERREIRA, Ferrando; POTT, Rejane Georgina. Personagens negros na literatura infantil brasileira na atualidade. 2014. Trabalho de Conclusão de Curso (Especialização em Educação da Relações Étnico-Raciais) - Núcleo de Estudos Afro-brasileiros, Universidade Federal do Paraná, Curitiba, 2014.

FERREIRA, Susan Alessandra de Sousa. Africanidades na educação infantil: Perspectivas para o Trabalho Educativo com a criança pequena. 2015. Trabalho de Conclusão de Curso (Especialização em Educação das Relações Étnico-Raciais) - Núcleo de Estudos Afrobrasileiros, Universidade Federal do Paraná, Curitiba, 2015. 
FREITAS, Sandra Ramos. Formação continuada de professores da rede estadual do Paraná para o ensino de história da cultura afro-brasileira e africana. 2010. Dissertação (Mestrado em Educação) - Departamento de Educação, PUC. Curitiba. 2010

FRIEDRICH, Rafael. Uma proposta de diálogo intercultural na formação de professores para alunos cotistas. 2015. Dissertação (Mestrado em Educação) - Universidade Federal de Santa Maria. Santa Maria. 2015.

GHIGGI, Gioconda. Análise da formação continuada de professoras e professores no núcleo de estudos afro-brasileiros na Universidade Federal do Paraná. 2017. Dissertação (Mestrado em Educação). Setor de Educação, UFPR. Curitiba. 2017.

IANSEN, Virgínia Aparecida. Educação Infantil: contribuição da literatura infantil de maneira positiva no desenvolvimento da identidade étnico-racial. 2015. Trabalho de Conclusão de Curso (Especialização em Educação das Relações Étnico-Raciais) - Núcleo de Estudos Afro-brasileiros, Universidade Federal do Paraná, Curitiba, 2015.

JESUS, Regina de Fática. Práticas pedagógicas evidenciam micro-ações afirmativas cotidianas. In: REUNIÃO ANUAL DA ANPED, $32^{\mathrm{a}}$. Caxambu, 2009. Anais... Caxambu: ANPED, 2009.

KEIK, Jane Roseli. História e cultura africana e afro-brasileira na Educação Infantil. 2015. Trabalho de Conclusão de Curso (Especialização em Educação das Relações ÉtnicoRaciais) - Núcleo de Estudos Afro-brasileiros, Universidade Federal do Paraná, Curitiba, 2015.

LUIZ, Maria Fernanda. Educação das relações étnico-raciais: Contribuiçõos de cursos de formação continuada para professoras (es). 2013. Dissertação (Mestrado em Educação) Programa de Pós-graduação em Educação, UFSCar. São Carlos. 2013.

MACHADO, Raimunda Nonata da Silva. Gênero e raça na educação a distância: há outras epistemologias na prática educativa de formação docente? 2015. Tese (Doutorado em Educação) - Universidade Federal do Piauí, 2015.

MARTINS, Francisco André Silva. É possível construir um outro continente africano na escola? experiências de um curso de aperfeiçoamento para professores. Revista da ABPN, v. 4, n. 8, p. 170-191, jul./out. 2012. Disponível em:

<http://abpn.org.br/Revista/index.php/edicoes/article/viewFile/244/220>. Acesso em: 03 Dez. 2017.

MARTINS, Regina. A importância dos personagens negros dentro da literatura infantil para valorização da diversidade. 2015. Trabalho de Conclusão de Curso (Especialização em Educação da Relações Étnico-Raciais) - Núcleo de Estudos Afro-brasileiros, Universidade Federal do Paraná, Curitiba, 2015.

NASCIMENTO, Adriana Cristina Zielinski do. Educação infantil: coordenação pedagógica e práticas de (re)educação das relações étnico-raciais no município de Pinhais-PR. 2015. Trabalho de Conclusão de Curso (Especialização em Educação da Relações Étnico-Raciais) - Núcleo de Estudos Afro-brasileiros, Universidade Federal do Paraná, Curitiba, 2015. 
OLIVEIRA, Eveline de. E agora professor, o que fazer com a Lei $\mathbf{n}^{\circ}$ 10.639/2003? 2015. Trabalho de Conclusão de Curso (Especialização em Educação das Relações ÉtnicoRaciais) - Núcleo de Estudos Afro-brasileiros, Universidade Federal do Paraná, Curitiba, 2015.

PALÚ, Valéria Pavão de Souza. O ensino da temática racial: formação e práticas docentes na educação escolar. 2011. Dissertação (Mestrado em Educação) - Faculdade de ciências e tecnologia, Universidade Estadual Paulista. Presidente Prudente. 2011.

PAULA, Benjamin Xavier de. A educação para as relações étnico-raciais e o estudo de história e cultura da África e afro brasileira: formação, saberes e práticas educativas. 2013. Tese (Doutorado em Educação) - Faculdade de Educação, Universidade Federal de Uberlândia. Uberlândia. 2013.

ROSA, Afrânio Gonsaga Ferreira da. História e cultura africana e afro-brasileira na Educação Infantil: a aplicação da Lei 10639/03 nos CMEIS da Prefeitura Municipal de São José dos Pinhais - Paraná. 2015. Trabalho de Conclusão de Curso (Especialização em Educação da Relações Étnico-Raciais) - Núcleo de Estudos Afro-brasileiros, Universidade Federal do Paraná, Curitiba, 2015.

SILVA, Marcella Padilha Dantas da Silva: BRANCO, Angela Uchoa. Negritude e infância: relações étnico-raciais em situação lúdica estruturada. Revista Psico, v. 42, n. 2, PP 197205, abr./jun. 2011.

SILVA, Maria da Anunciação Conceição. Formação docente: do infinito ao particular! Narrativas sobre gênero, raça e religião. Revista Tempos e Espaços em Educação, São Cristóvão, v. 7, n. 12. jan./abr. 2014. Disponível em:

<http://www.seer.ufs.br/index.php/revtee/article/view/2960/2605>. Acesso em: 04 Jan. 2017.

VASCONCELOS, Fátima. Bonecas: objeto de conflito identitário na arena da dominação cultural. In: REUNIÃO ANUAL DA ANPED, 27. Programa e resumos. Caxambu : Associação Nacional de Pós-graduação e Pesquisa em Educação, 2004. 